\title{
Optimization of $\mathrm{Mo} / \mathrm{Cr}$ bilayer back contacts for thin-film solar cells
}

\author{
Nima Khoshsirat ${ }^{1}$, Fawad Ali ${ }^{1}$, Vincent Tiing Tiong ${ }^{1}$, Mojtaba Amjadipour ${ }^{1}$, \\ Hongxia Wang ${ }^{1}$, Mahnaz Shafiei ${ }^{1,2}$ and Nunzio Motta*1
}

\author{
Full Research Paper \\ Address: \\ ${ }^{1}$ School of Chemistry, Physics, Mechanical Engineering, Queensland \\ University of Technology (QUT), Brisbane, Australia and ${ }^{2}$ Swinburne \\ University of Technology, Melbourne, Australia \\ Email: \\ Nunzio Motta* - n.motta@qut.edu.au \\ * Corresponding author \\ Keywords: \\ back contact; bilayer; chromium; DC sputtering; molybdenum; optical \\ reflectance
}

\author{
Beilstein J. Nanotechnol. 2018, 9, 2700-2707. \\ doi:10.3762/bjnano.9.252 \\ Received: 21 May 2018 \\ Accepted: 21 September 2018 \\ Published: 18 October 2018 \\ Associate Editor: T. Glatzel \\ (C) 2018 Khoshsirat et al.; licensee Beilstein-Institut. \\ License and terms: see end of document.
}

\begin{abstract}
Molybdenum (Mo) is the most commonly used material as back contact in thin-film solar cells. Adhesion of Mo film to soda-lime glass (SLG) substrate is crucial to the performance of solar cells. In this study, an optimized bilayer structure made of a thin layer of Mo on an ultra-thin chromium (Cr) adhesion layer is used as the back contact for a copper zinc tin sulfide (CZTS) thin-film solar cell on a SLG substrate. DC magnetron sputtering is used for deposition of Mo and Cr films. The conductivity of Mo/Cr bilayer films, their microstructure and surface morphology are studied at different deposition powers and working pressures. Good adhesion to the SLG substrate has been achieved by means of an ultra-thin Cr layer under the Mo layer. By optimizing the deposition conditions we achieved low surface roughness, high optical reflectance and low sheet resistivity while we could decrease the back contact thickness to $600 \mathrm{~nm}$. That is two thirds to half of the thickness that is currently being used for bilayer and single layer back contact for thin-film solar cells. We demonstrate the excellent properties of $\mathrm{Mo} / \mathrm{Cr}$ bilayer as back contact of a CZTS solar cell.
\end{abstract}

\section{Introduction}

Molybdenum (Mo) thin films are widely used as a back contact for photovoltaic devices such as $\mathrm{Cu}\left(\operatorname{In}_{1-x} \mathrm{Ga}_{x}\right) \mathrm{S}_{2}$ (CIGS) and $\mathrm{Cu}_{2} \mathrm{ZnSnS}_{4}$ (CZTS) thin-film solar cells. The back contact is the first layer to be deposited and its properties have significant effects on the solar cell performance. This layer acts as an optical reflector to the photons that are not absorbed in the active medium, and as a metallic contact layer to transport drive out the photo-generated carriers $[1,2]$. In addition to these electro-optical properties, the back contact material should have a higher work function than the neighboring light-absorbing semiconductor layer [3]. Accordingly, different metal contacts (such as Al, Au, Cr, Mn, Mo, Pt, Ti, V and W) have been used as back contact layer in thin-film solar cells [4-7]. Among these elements, Mo is reported to have a relatively better stability at the elevated temperatures required for the fabrication of CIGS and CZTS, better ohmic contact behavior, lower resistivity and 
a higher work function than the CIGS and CZTS lightabsorbing semiconductor layers. However, the most challenging part in the deposition of the Mo thin film using a DC sputter system is to find the right compromise between the adhesion of the film to the substrate (mostly soda-lime glass (SLG)) and its electro-optical properties. It is well known that the film adhesion and its conductivity show opposite trends as a functions of the sputtering power and pressure [8,9]. The most successful approach suggested so far to improve the adhesion of Mo back contact layer to the glass substrate (while retaining its conductivity and optical reflectance) is through the deposition of a Mo bilayer rather than a single layer [10-13]. This involves the deposition of a thick Mo layer with low resistivity at low pressure and high sputtering power on a thin Mo layer deposited at high pressure and low power providing the required adhesion to the substrate. However, this method still does not guarantee the adhesion of the film to the substrate and the Mo back contact layer could peel off from the substrate during the absorber layer growth at high temperatures or during the deposition of the buffer layer, which most commonly involves a wet chemical process. Moreover, the thickness of the bilayer Mo film needs to be in the range of $900 \mathrm{~nm}$ to $1.2 \mu \mathrm{m}$ to achieve a good conductivity. One of our goals in this work was to reduce the back contact thickness, which would lead to cost reduction [14$16]$.

$\mathrm{Cr}$ is a well-known adhesion layer, traditionally used to increase the adhesion of metallic films to substrates such as glass or stainless steel [17-21]. Cr forms an oxide interface layer by scavenging the oxygen available on the glass surface during the sputtering process. This creates nucleation centers and promotes nucleation of the next deposited material (in this case Mo), leading to a strong adhesion of Mo to the substrates [22-24]. $\mathrm{The} \mathrm{Mo} / \mathrm{Cr}$ back contact has been already proposed in flexible thin-film solar cells on metallic foils and stainless steel [25-28]. However, in these reports $\mathrm{Cr}$ was used as a barrier layer to reduce/prevent impurity out-diffusion from the metallic substrate to the absorber layer and its effect on the adhesion of the back contact was not studied. In spite of the importance of this topic for the development of thin-film solar cells, there are very few reports regarding the application of $\mathrm{Cr}$ as an adhesion layer in back contacts $[29,30]$. Notably, the influence of $\mathrm{Cr}$ on the properties of the back contact and on the total performance of the solar cell is still a subject of debate and some studies negatively correlates $\mathrm{Cr}$ with a low performance of the cell due to its diffusion in the absorber layer [31]. In this work we exploit the adhesive properties of $\mathrm{Cr}$ to develop a new protocol that improves the adhesion of the Mo back contact layer to the substrate and demonstrate the excellent electro-optical properties of the $\mathrm{Mo} / \mathrm{Cr}$ film for solar cells applications. The morphological and optical properties of the deposited films have been investi- gated using scanning electron microscopy (SEM), atomic force microscopy (AFM), UV-vis-NIR spectroscopy and X-ray photoelectron spectroscopy. A careful analysis of the resulting $\mathrm{Mo} / \mathrm{Cr}$ thin film across all the sputtering parameters led us to the best combination, optimizing both the electro-optical response of the $\mathrm{Mo} / \mathrm{Cr}$ bilayer and the adhesion of the film to the substrate while we could reduce the required thickness to $600 \mathrm{~nm}$. That is at most two thirds of reported thickness for Mo back contacts for thin-film solar cells.

\section{Experimental Film deposition}

A $10-15 \mathrm{~nm}$ thick layer of $\mathrm{Cr}$ was deposited on a $2.5 \times 2.5 \mathrm{~cm}$ SLG substrate using a Kurt J. Lesker PVD75 DC magnetron sputtering system operated at $40 \mathrm{~W}$ and $10 \mathrm{mTorr}$ for $10 \mathrm{~min}$, from a 2 inch Cr target (Kurt J. Lesker, 99.95\% purity). The Mo layer was deposited on uncoated and $\mathrm{Cr}$-coated substrates by using a 2 inch Mo target (Kurt J. Lesker, 99.95\% purity) at different working pressures (3, 5 and $10 \mathrm{mTorr})$ and different sputtering powers of $(100,150$ and $200 \mathrm{~W})$. In order to start under the same conditions for all depositions, the vacuum chamber was evacuated before each deposition round to the base pressure of $1 \times 10^{-7}$ Torr, and the targets were pre-sputtered for 10 min with Argon in order to remove any oxide layer or contamination. During the deposition, the substrates were continuously rotating with a speed of $20 \mathrm{rpm}$ to ensure a homogeneous coverage all over the substrate surface. The sputtering time was determined from the deposition rate under different working conditions and was set to obtain Mo layers with $600 \mathrm{~nm}$ thickness.

\section{Film characterization}

The film thickness measurements were conducted using a Bruker Dektak stylus profiler. Morphology studies and surface roughness measurements were carried out using a JEOL 7001F scanning electron microscope (SEM) and a tapping mode NT-MDT Solver-Pro atomic force microscope (AFM). A KeithLink four-point probe system was used to measure the sheet resistivity of the films. A Cary 5000 UV-vis-NIR spectrophotometer was also used for the optical properties measurements. The adhesion of the Mo layer was tested through ultra-sonication of the samples at $50{ }^{\circ} \mathrm{C}$ in the presence of sodium hydroxide solution ( $2 \mathrm{wt} \%$ in deionized water) for $10 \mathrm{~min}$. The crystal structure of Mo films has been analyzed using a Rigaku SmartLab X-ray diffraction (XRD) spectrometer with monochromatic $\mathrm{Cu} \mathrm{K} \alpha(40 \mathrm{kV}, 40 \mathrm{~mA}, \lambda=0.154 \mathrm{~nm})$ as an excitation source operating in parallel beam mode with a Hypix 3000 detector (0D mode). The incidence angle $(\alpha)$ was fixed to $1^{\circ}$ during data collection. The incident optics were a $5^{\circ}$ Soller slit, $10 \mathrm{~mm}$ incident slit and a $0.137 \mathrm{~mm}$ divergence slit. Receiving optics were a $0.114^{\circ}$ collimator and $20 \mathrm{~mm}$ receiving slits. 
Patterns were collected for $1 \mathrm{~h}$ at a step size of $0.01^{\circ}$ from 10 to $85^{\circ} 2 \theta$ at $1.3^{\circ}$ per minute over the $2 \theta$ axis.

X-ray photoelectron spectroscopy (XPS) was performed using a Kratos Axis Supra with Al Ka X-ray radiation ( $h v 1486.7 \mathrm{eV}$ ) High-resolution scans of the $\mathrm{O} 1 \mathrm{~s}, \mathrm{C} 1 \mathrm{~s}, \mathrm{Na} 1 \mathrm{~s}, \mathrm{Cr} 2 \mathrm{p}, \mathrm{Na} 1 \mathrm{~s}$ and $\mathrm{Mo} 3 \mathrm{~d}$ regions were acquired with $10 \mathrm{eV}$ pass energy and about $0.4 \mathrm{eV}$ spectral resolution to discriminate the substructure of the spectral lines. $\mathrm{Ar}^{+}$ion cluster etching was employed for XPS depth profiling and the calibration was carried out using a typical Mo on glass sample with sputtering rate of $15.5 \mathrm{~nm} / \mathrm{s}$. Depth profiling was conducted on a $1 \times 1 \mathrm{~mm}^{2}$ area with a $\mathrm{Ar}^{+}$ ion beam energy of $10 \mathrm{keV}$ and large cluster size $(n=2000)$.

\section{Results and Discussion \\ Adhesion}

The first characterization step was the adhesion test performed on Mo layers after deposition on uncoated and $\mathrm{Cr}$-coated glass substrates. All samples deposited on uncoated glass showed poor adhesion to the substrate, while a thin layer of $\mathrm{Cr}$ significantly improved the adhesion of Mo layer to the substrate (see Supporting Information File 1).

Figure 1 shows pictures of some samples after the adhesion test. It is evident how the Mo layer is peeling off from the uncoated glass substrate (Figure 1a-c) failing the adhesion test, while the same layer deposited on Cr-coated glass substrates does not peel off (Figure 1d-f).

\section{Resistivity}

Besides the good adhesion to the substrate, the metallic back contact layer in thin-film solar cells should have low resistivity to be able to drive out the photo-generated carriers to the external load. Sheet resistivity for a typical back contact layer should not be larger than $1 \Omega /$ sq. Measurements using a fourpoint probe were performed only on samples that passed the adhesion test. Figure 2 shows the variation of $\mathrm{Mo} / \mathrm{Cr}$ bilayer electrical resistivity at different deposition pressures with

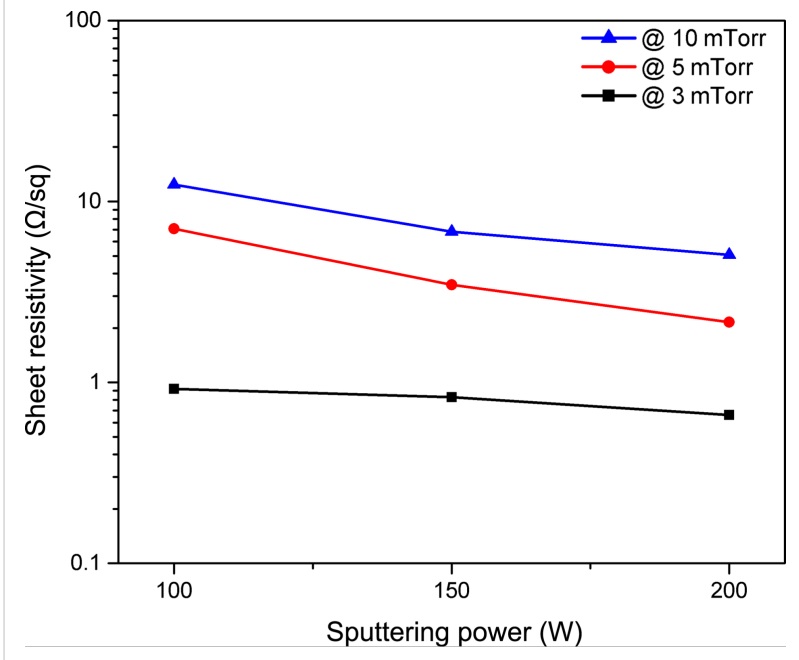

Figure 2: Sheet resistivity of $\mathrm{Mo} / \mathrm{Cr}$ films prepared at different values of sputtering power and pressure.

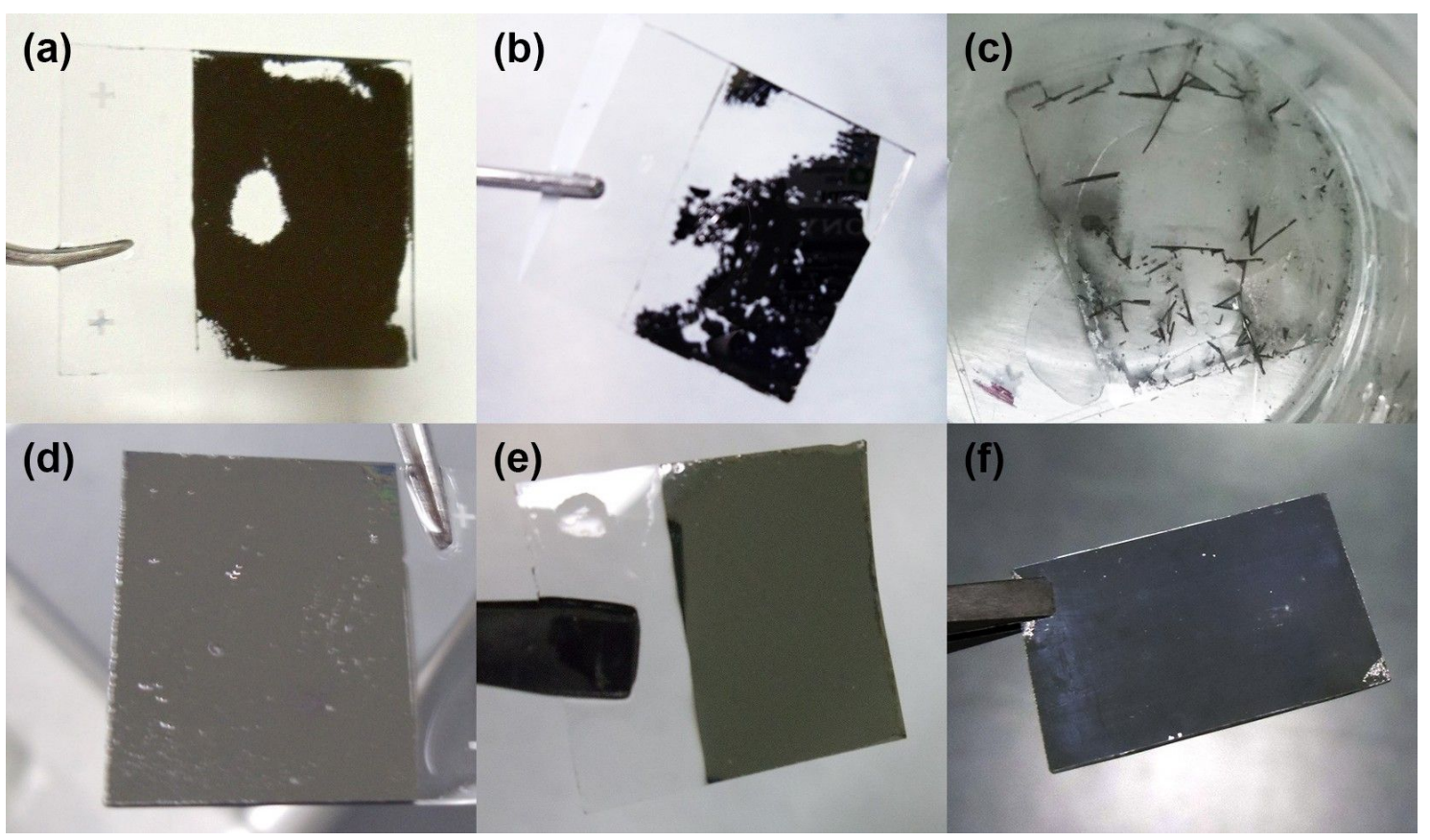

Figure 1: Samples after adhesion test. (a-c) Mo/SLG; (d-f) Mo/Cr/SLG. (a, d) 100 W, 10 mTorr, (b, e) 150 W, 5 mTorr, (c, f) 200 W, 3 mTorr. 
respect to the sputtering power. As can be seen, the resistivity of $\mathrm{Mo} / \mathrm{Cr}$ bilayer is directly proportional to the working pressure, while it shows an inverse relation to the sputtering power. Accordingly, the resistivity of the layers reduces by increasing the sputtering power. The decrease in resistivity due to the increase of sputtering power is more drastic at 10 and 5 mTorr compared to the samples prepared at 3 mTorr. Samples deposited at $10 \mathrm{mTorr}$ show high sheet resistivity, even at high sputtering power $(5.07 \Omega / \mathrm{sq}=304.2 \mu \Omega \cdot \mathrm{cm}$ at $200 \mathrm{~W})$, unsuitable for back contacts of thin-film solar cells. The lowest resistivity is shown by films prepared at $3 \mathrm{mTorr}$ and $200 \mathrm{~W}$ $(0.66 \Omega / \mathrm{sq}=39.6 \mu \Omega \cdot \mathrm{cm})$, falling in the required range for back contacts. This range of conductivity has been reported for bilayer Mo films with thickness values in the range of 0.9 to $1.2 \mu \mathrm{m}$ [14-16], which is 1.5 -times the value of our samples.

The decreasing of the film resistivity with increasing sputtering power could be attributed to the effect of power on the microstructure of the film. Higher power leads to bigger grain sizes, as higher kinetic energies of the atoms favor the coalescence of grains. Similarly, low pressure leads to higher grain sizes due to the lower number of collisions and the higher energy of atoms landing on the substrate $[9,32,33]$. As shown in Figure 3, the films deposited at lower pressure and higher power have larger and more dense grains as compared with the films deposited at higher pressure and lower power. This results in less grain boundaries and consequently higher carrier mobility and conductivity.

The SEM images also show more uniform surfaces over the film area for the samples deposited at 3 mTorr compared with those films deposited at 5 mTorr. Blister-shaped features appeared on the samples deposited at $5 \mathrm{mTorr}$ possibly due to micro-bubbles of Ar gas trapped in the Mo layer [34]. The appearance of blisters on the sample surface decreases when the sputtering power is increased. The differences in surface morphology are also confirmed by AFM images (see Supporting Information File 1). AFM roughness analysis (Figure 4) reveals an increase of the surface roughness with the sputtering power. Surface roughness is also directly proportional to the working pressure. The average roughness increases from 1.61 to $3.06 \mathrm{~nm}$ in samples deposited at $3 \mathrm{mTorr}$ and from 2.78 to $3.81 \mathrm{~nm}$ in samples deposited at $5 \mathrm{mTorr}$, when the power is raised from 100 to $200 \mathrm{~W}$, confirming the grain size increase visible in the

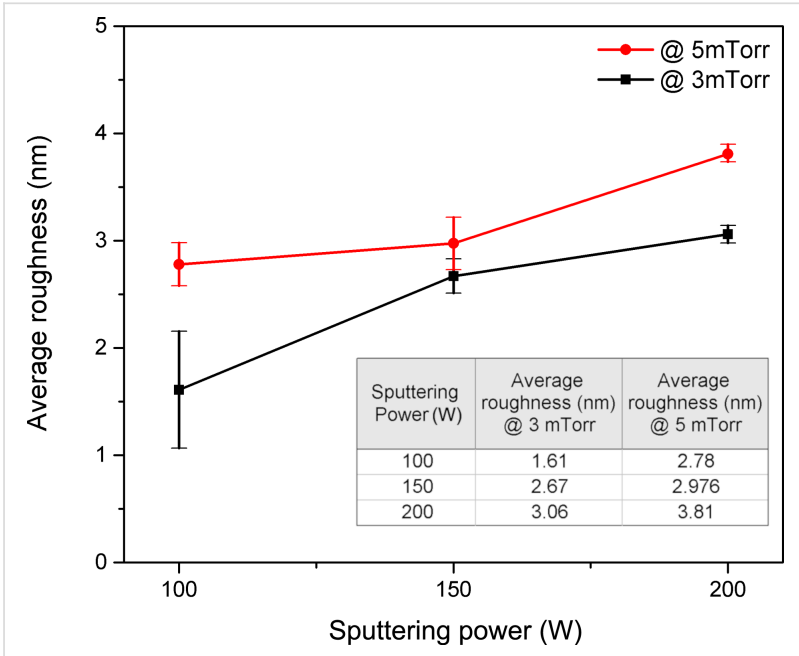

Figure 4: Average surface roughness of $\mathrm{Mo} / \mathrm{Cr}$ films prepared at different sputtering powers and pressures.

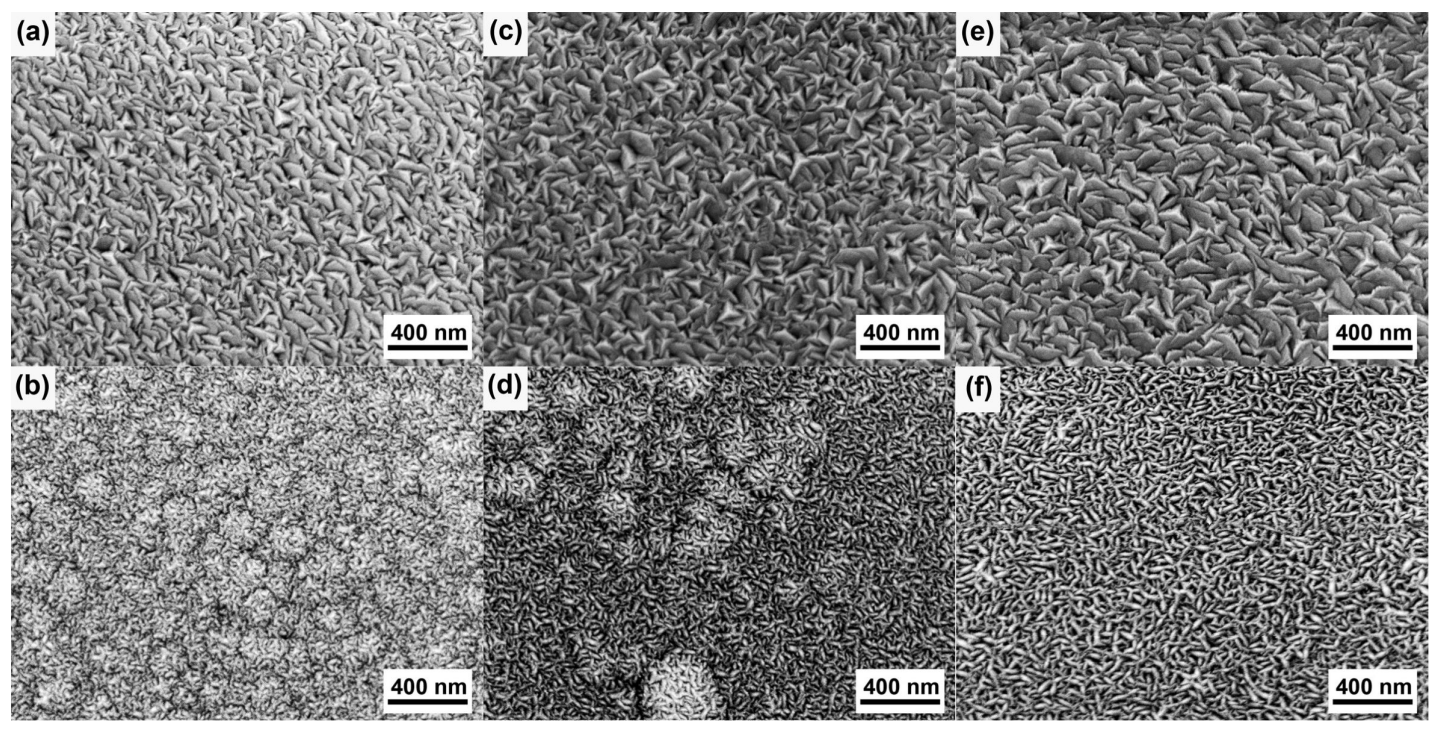

Figure 3: Surface SEM images of Mo/Cr films prepared at sputtering power and pressure values of (a) $100 \mathrm{~W}, 3 \mathrm{mTorr}$, (b) $100 \mathrm{~W}, 5 \mathrm{mTorr}$, (c) 150 W, 3 mTorr, (d) 150 W, 5 mTorr, (e) 200 W, 3 mTorr and (f) 200 W, 5 mTorr. 
SEM results (Figure 3), as higher power leads to denser and bigger grains.

\section{X-ray diffraction (XRD) pattern and crystallinity}

The XRD spectra of Mo films grown on Cr-coated glass using different values of sputtering power and pressure are shown in Figure 5. All samples exhibit three main peaks that match with the (110), (200) and (211) plane orientations of the standard difractogram ICDD-96-901-1606 for Mo. A comparison of XRD peak intensities shows a higher peak intensity for samples deposited at 3 mTorr. This is another evidence for increased crystallinity at lower deposition pressure. A similar trend can also be seen in Figure 5 when the sputtering power increases from 100 to $200 \mathrm{~W}$.

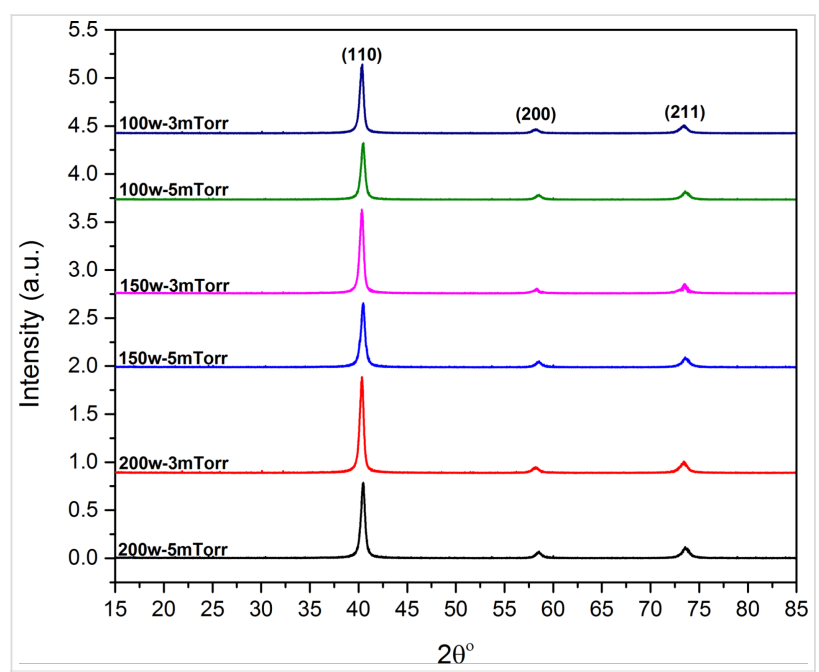

Figure 5: X-ray diffraction peaks of $\mathrm{Mo} / \mathrm{Cr}$ films prepared using different values of sputtering power and pressure.

XRD patterns of all samples exhibit a dominant (110) orientation. Previous studies revealed that the (110) Mo crystal orientation can enhance the (220) and (204) CIGS and (112) CZTS orientations, which leads to a decrease of grain boundary recombination losses and series resistance in CIGS and CZTS thin-film solar cells $[35,36]$. Table 1 shows the summary of the analysis of the (110) peaks. The FWHM values of the samples prepared at lower pressure are lower, which also confirms the presence of larger crystalline grains at low deposition pressures.

\section{Optical properties}

Another important characteristic of a good back contact layer is its optical reflectance. A back contact layer with high optical reflectance can contribute effectively to the light absorption by reflecting the non-absorbed photons back to the absorber layer. The optical reflectance of the the $\mathrm{Mo} / \mathrm{Cr}$ bilayer was measured in the wavelength range of $200-1800 \mathrm{~nm}$. As shown in
Table 1: X-ray diffraction analysis of peak along the (110) plane.

\begin{tabular}{llll} 
sample & $\begin{array}{l}(110) \text { peak } \\
\text { FWHM } \\
\pm 0.001\end{array}$ & $\begin{array}{l}(110) \text { peak } \\
\text { position } \\
\pm 0.01\end{array}$ & $\begin{array}{l}110 /(\text { all } \\
\text { peaks) }\end{array}$ \\
\hline 100W-5mTorr & 0.450 & $40.454^{\circ}$ & 0.75 \\
150W-5mTorr & 0.478 & $40.452^{\circ}$ & 0.74 \\
200W-5mTorr & 0.451 & $40.453^{\circ}$ & 0.74 \\
100W-3mTorr & 0.430 & $40.326^{\circ}$ & 0.77 \\
150W-3mTorr & 0.431 & $40.325^{\circ}$ & 0.81 \\
200W-3mTorr & 0.430 & $40.325^{\circ}$ & 0.77
\end{tabular}

Figure 6, films deposited at 3 mTorr have higher reflectance than those deposited at $5 \mathrm{mTorr}$. UV-visible spectroscopy results also revealed that the optical reflectance of the films slightly decreases after increasing the sputtering power, due to the roughness increase. In order to quantify the reflectance variation due to changes in deposition power and pressure, the area under each reflectance curve was calculated by numerical integration and called integral reflectance. Integral reflectance shows a $1.38 \%$ increase when the sputtering power decreases from 200 to $150 \mathrm{~W}$ and a $2.21 \%$ further increase when the power decreases to $100 \mathrm{~W}$, for samples deposited at $3 \mathrm{mTorr}$, in general agreement with reports on single-layer or bilayer Mo films [4,37-39]. It should be noted however, that our DC-sputtered $\mathrm{Mo} / \mathrm{Cr}$ bilayer shows an overall optical reflectance of $60-65 \%$ in the visible range, which is much higher than previously reported sputtered Mo films (35-60\%) [8-10,37-40]. This is mostly due to lower surface roughness of our samples.

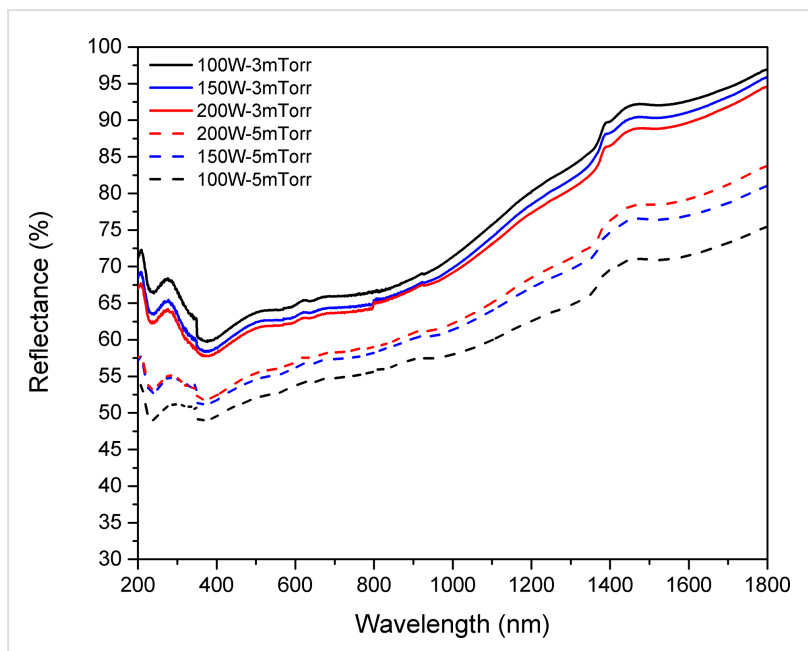

Figure 6: Optical reflectance of $\mathrm{Mo} / \mathrm{Cr}$ films prepared using different values of sputtering power and pressure.

\section{Diffusion of chromium and sodium}

It is known that in CIGS and CZTS thin-film solar cells diffusion of sodium from the SLG substrate to the absorber layer is 
beneficial and can enhance the electro-optical properties of the absorber layer [41-45]. On the other side, $\mathrm{Cr}$ incorporation in CIGS absorber layer reduces the cell performance due to creation of deep defect levels in the CIGS layer [46]. In order to investigate the diffusion mechanism of $\mathrm{Cr}$ and $\mathrm{Na}$ to the top layer, we first heated the $\mathrm{Mo} / \mathrm{Cr}$ films on SLG to $550{ }^{\circ} \mathrm{C}$ for $30 \mathrm{~min}$ in argon atmosphere. This is the temperature that is normally used for sulfurization and selenization of CIGS and CZTS layers. Then XPS depth profiling was performed on the annealed $\mathrm{Mo} / \mathrm{Cr}$ films to search for any $\mathrm{Cr}$ or $\mathrm{Na}$ signal in the Mo layer, by etching the film via argon gas cluster ions for 4 min before each XPS acquisition until the signal from the substrate was visible. The result is shown in Figure 7 for a Mo/Cr film deposited at $200 \mathrm{~W}$ and $3 \mathrm{mTorr}$ (high-resolution spectra of Mo $3 \mathrm{~d}$ and $\mathrm{Cr} 2 \mathrm{p}$ are provided in Supporting Information File 1).

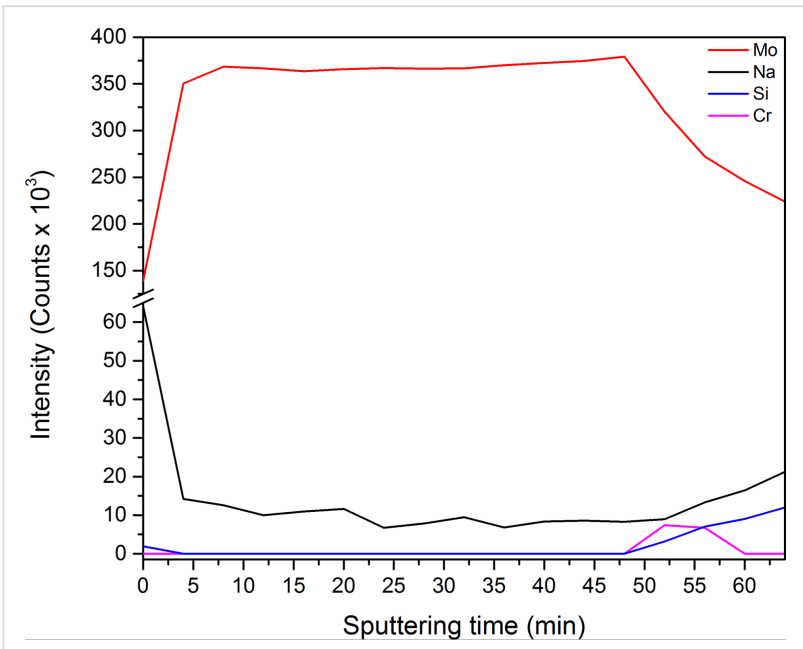

Figure 7: XPS depth profile of the Mo/Cr films deposited at $200 \mathrm{~W}$ and 3 mTorr.

The profile clearly shows the presence of sodium throughout Mo layer and even on the surface which means that the thin $\mathrm{Cr}$ adhesion layer is not stopping $\mathrm{Na}$ diffusion from SLG to the top layers. No $\mathrm{Cr}$ signal has been detected in the Mo layer. $\mathrm{Cr}$ signal starts to increase at 50 min sputtering, exactly when the Mo signal starts to drop, and then drops to zero at around 60 min, confirming that $\mathrm{Cr}$ does not diffuse in the Mo layer and is just acting as an adhesion layer.

\section{Applying the developed $\mathrm{Mo} / \mathrm{Cr}$ bilayer in a CZTS thin-film solar cell}

The bilayer Mo/Cr stacks developed in this work seems to be a good option to be used as a back contact in thin-film solar cells. In order to prove this a CZTS thin-film solar cell has been made by stacking the ITO/ZnO/CdS/ $\mathrm{Cu}_{2} \mathrm{ZnSnS}_{4}$ on top of $\mathrm{Mo} / \mathrm{Cr}$ bilayer back contact on the SLG substrate. A $1.5 \mu \mathrm{m}$ thick CZTS was deposited through a two-step process of sulfurization of stacked metallic layers of $\mathrm{Cu} / \mathrm{Sn} / \mathrm{Zn}$. Then a $60 \mathrm{~nm} \mathrm{CdS}$ buffer layer was deposited using chemical bath deposition (CBD). This was followed by sputtering of a $30 \mathrm{~nm} \mathrm{ZnO} \mathrm{layer} \mathrm{and} \mathrm{a}$ $350 \mathrm{~nm}$ ITO layer as transparent conductive oxide (TCO) layers. As the last step, a silver collection grid was deposited on top using electron-beam evaporation. It is worth mentioning that the fabrication of a cell on a single-layer Mo-coated glass also has been tried. However, the Mo films were peeled-off from the substrate during CdS CBD. Thus, herein only the performance of a cell with $\mathrm{Mo} / \mathrm{Cr}$ bilayer back contact is reported. Figure 8 shows the $J-V$ characteristics of the CZTS cell with $\mathrm{Mo} / \mathrm{Cr}$ bilayer back contact. In this first attempt it is clear that the device is working with a reasonable fill factor (54.38\%). The efficiency of the cell was $1.86 \%$, calculated over an area of $0.173 \mathrm{~cm}^{2}$. This measurement confirms the functionality of the Mo/Cr bilayer back contact for CZTS thin-film solar cells. A substantial improvement of the performance is expected to come through an optimization of the electro-optical properties of the layers, which is the subject of further studies.

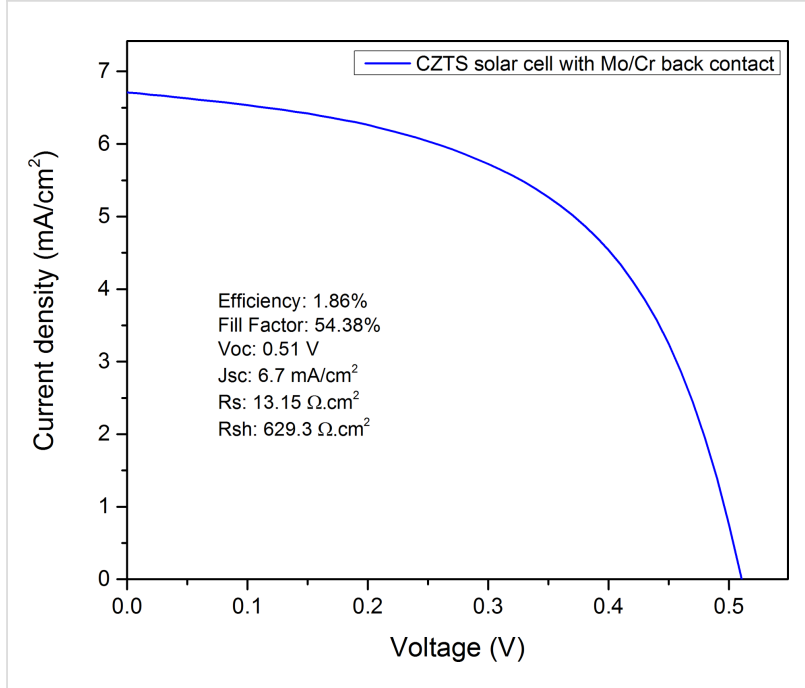

Figure 8: $J-V$ characteristics of the CZTS cell with $\mathrm{Mo} / \mathrm{Cr}$ bilayer back contact.

\section{Conclusion}

A bilayer of $\mathrm{Mo} / \mathrm{Cr}$ thin films with robust adhesion and desired electro-optical properties as a back contact in thin-film solar cells was successfully deposited on SLG substrates using DC sputtering. The bottom 10-15 nm thick Cr layer was used to increase the adhesion of the top Mo layer to the substrate. The experimental results indicate that the Cr layer can significantly improve the adhesion of Mo layer to the glass substrate even for samples that are deposited at high power and low pressure. The lowest electrical resistivity $(0.66 \Omega / \mathrm{sq})$ was observed for a sample with Mo layer deposited at $200 \mathrm{~W}$ sputtering power and 
3 mTorr working pressure. The optical reflectance in the visible range was found to be over $60 \%$ for samples deposited at 3 mTorr. The excellent adhesion of $\mathrm{Mo} / \mathrm{Cr}$ bilayer to the substrate, its low resistivity and high optical reflectance achieved in this study are matching the requirements for an optimum back contact in CIGS and CZTS thin-film solar cells. The developed $\mathrm{Mo} / \mathrm{Cr}$ bilayer has been tried in a CZTS thin-film solar cells showing promising values of fill factor and series resistance.

\section{Supporting Information}

\section{Supporting Information File 1}

Additional experimental data.

[https://www.beilstein-journals.org/bjnano/content/

supplementary/2190-4286-9-252-S1.pdf]

\section{Acknowledgements}

This research was mainly performed at the Institute for Future Environments (IFE) Central Analytical Research Facility (CARF), QUT. Access to CARF is supported by generous funding from the Science and Engineering Faculty (QUT). The authors appreciate the technical assistance of Dr. Peter Hines. The authors acknowledge the support of the Queensland Government through the Q-CAS Collaborative Science Fund 2016. N.K. would like to acknowledge the QUTPRA scholarship scheme for financial support. H.W. acknowledges the financial support of the Australian Research Council (ARC) Future Fellow Scheme (FT/20/00674). M.S. acknowledges funding from Australian Research Council- Discovery Project (ARC DP150101939).

\section{ORCID ${ }^{\circledR}$ iDs}

Nima Khoshsirat - https://orcid.org/0000-0002-1133-7923

Fawad Ali - https://orcid.org/0000-0003-1454-1433

\section{References}

1. Scheer, R.; Schock, H.-W. Chalcogenide photovoltaics: physics, technologies, and thin film devices; John Wiley \& Sons: New York City, NY, U.S.A., 2011. doi:10.1002/9783527633708

2. Khoshsirat, N.; Yunus, N. A. M. Copper-Indium-Gallium-diSelenide (CIGS) Nanocrystalline Bulk Semiconductor as the Absorber Layer and Its Current Technological Trend and Optimization. Nanoelectronics and Materials Development; InTech: Rijeka, Croatia, 2016. doi: $10.5772 / 64166$

3. Gupta, N. Mater. Des. 2011, 32, 1667-1671. doi:10.1016/j.matdes.2010.10.002

4. Orgassa, K.; Schock, H. W.; Werner, J. H. Thin Solid Films 2003, 431-432, 387-391. doi:10.1016/s0040-6090(03)00257-8

5. Dicov, C.; Marinov, M.; Maciel, H.; Grigorov, K.; Nedkov, I.; Beshkov, G. J. Optoelectron. Adv. Mater. 2005, 7, 385-387.
6. Oueslati, S.; Brammertz, G.; Buffière, M.; ElAnzeery, H.; Mangin, D.; EIDaif, O.; Touayar, O.; Köble, C.; Meuris, M.; Poortmans, J. J. Phys. D: Appl. Phys. 2015, 48, 035103. doi:10.1088/0022-3727/48/3/035103

7. Altamura, G.; Grenet, L.; Roger, C.; Roux, F.; Reita, V.; Fillon, R.; Fournier, H.; Perraud, S.; Mariette, H. J. Renewable Sustainable Energy 2014, 6, 011401. doi:10.1063/1.4831781

8. Pethe, S. A.; Takahashi, E.; Kaul, A.; Dhere, N. G. Sol. Energy Mater. Sol. Cells 2012, 100, 1-5. doi:10.1016/j.solmat.2011.11.038

9. Li, W.; Yan, X.; Aberle, A. G.; Venkataraj, S. Jpn. J. Appl. Phys. 2015, 54, 08KC14. doi:10.7567/jjap.54.08kc14

10. Li, W.; Yan, X.; Aberle, A. G.; Venkataraj, S. Int. J. Photoenergy 2016, 2124087. doi:10.1155/2016/2124087

11. Wang, S.-F.; Yang, H.-C.; Liu, C.-F.; Bor, H.-Y. Y. Adv. Mater. Sci. Eng 2014, 2014, 531401. doi:10.1155/2014/531401

12. Salomé, P. M. P.; Malaquias, J.; Fernandes, P. A.; Cunha, A. F. d. J. Phys. D: Appl. Phys. 2010, 43, 345501. doi:10.1088/0022-3727/43/34/345501

13. Li, Z.-H.; Cho, E.-S.; Kwon, S. J. Appl. Surf. Sci. 2011, 257, 9682-9688. doi:10.1016/j.apsusc.2011.06.101

14. Liu, X.; Cui, H.; Hao, X.; Huang, S.; Conibeer, G. J. Korean Phys. Soc. 2017, 71, 968-973. doi:10.3938/jkps.71.968

15. Huang, P. C.; Sung, C. C.; Chen, J. H.; Huang, C. H.; Hsu, C. Y. Appl. Surf. Sci. 2017, 425, 24-31. doi:10.1016/j.apsusc.2017.06.247

16. Chelvanathan, P.; Shahahmadi, S. A.; Arith, F.; Sobayel, K.; Aktharuzzaman, M.; Sopian, K.; Alharbi, F. H.; Tabet, N.; Amin, N. Thin Solid Films 2017, 638, 213-219. doi:10.1016/j.tsf.2017.07.057

17. Vianco, P. T.; Conley, W. R.; Panitz, J. K. G. Resistivity, adhesive strength, and residual stress measurements of thin film metallizations on single crystal quartz. In 44th Annual Symposium on Frequency Control, IEEE Publishing: Piscataway, NJ, U.S.A., 1990; pp 207-215. doi:10.1109/freq.1990.177499

18. Russell, S. W.; Rafalski, S. A.; Spreitzer, R. L.; Li, J.; Moinpour, M.; Moghadam, F.; Alford, T. L. Thin Solid Films 1995, 262, 154-167. doi:10.1016/0040-6090(94)05812-1

19. Santato, C.; Cicoira, F.; Cosseddu, P.; Bonfiglio, A.; Bellutti, P.; Muccini, M.; Zamboni, R.; Rosei, F.; Mantoux, A.; Doppelt, P. Appl. Phys. Lett. 2006, 88, 163511. doi:10.1063/1.2193468

20. Najiminaini, M.; Vasefi, F.; Kaminska, B.; Carson, J. J. L. Opt. Express 2011, 19, 26186-26197. doi:10.1364/oe.19.026186

21. Cho, J.-S.; Baek, S.; Lee, J. C. Sol. Energy Mater. Sol. Cells 2011, 95 , 1852-1858. doi:10.1016/j.solmat.2011.02.007

22. Poley, N. M.; Whitaker, H. L. J. Vac. Sci. Technol. (N. Y., NY, U. S.) 1974, 11, 114-118. doi:10.1116/1.1318538

23. Onyiriuka, E. C.; Kinney, L. D.; Binkowski, N. J. J. Adhes. Sci. Technol. 1997, 11, 929-940. doi:10.1163/156856197x00507

24. Jiang, N.; Silcox, J. MRS Online Proc. Libr. 1999, 589, 377. doi:10.1557/proc-589-377

25. Khelifi, S.; Belghachi, A.; Lauwaert, J.; Decock, K.; Wienke, J.; Caballero, R.; Kaufmann, C. A.; Burgelman, M. Energy Procedia 2010, 2, 109-117. doi:10.1016/j.egypro.2010.07.017

26. Cho, D.-H.; Chung, Y.-D.; Lee, K.-S.; Kim, K.-H.; Kim, J.-H.; Park, S.-J.; Kim, J. Curr. Appl. Phys. 2013, 13, 2033-2037. doi:10.1016/j.cap.2013.09.005

27. Donzel-Gargand, O.; Thersleff, T.; Fourdrinier, L.; Leifer, K.; Edoff, M. Thin Solid Films 2016, 619, 220-226. doi:10.1016/j.tsf.2016.10.063

28. Kim, K.-B. Appl. Sci. Convergence Technol. 2017, 26, 16-19. doi:10.5757/asct.2017.26.1.16 
29. Alleman, J.; Ginley, D.; Hasoon, F.; Asher, S.; Noufi, R. MRS Online Proc. Libr. 1996, 426, 195. doi:10.1557/proc-426-195

30. Britt, J. S.; Huntington, R.; VanAlsburg, J.; Wiedeman, S.; Beck, M. E. Cost improvement for flexible CIGS-based product. In 2006 IEEE 4th World Conference on Photovoltaic Energy Conference, IEEE Publishing: Piscataway, NJ, U.S.A., 2006; pp 388-391. doi:10.1109/wcpec.2006.279471

31. Batchelor, W. K.; Beck, M. E.; Huntington, R.; Repins, I. L.; Rockett, A.; Shafarman, W. N.; Hasoon, F. S.; Britt, J. S. Substrate and back contact effects in CIGS devices on steel foil. In Conference Record of the Twenty-Ninth IEEE Photovoltaic Specialists Conference 2002, IEEE Publishing: Piscataway, NJ, U.S.A., 2002; pp 716-719. doi:10.1109/pvsc.2002.1190665

32. Vink, T. J.; Somers, M. A. J.; Daams, J. L. C.; Dirks, A. G. J. Appl. Phys. 1991, 70, 4301-4308. doi:10.1063/1.349108

33. Scofield, J. H.; Duda, A.; Albin, D.; Ballard, B. L.; Predecki, P. K. Thin Solid Films 1995, 260, 26-31. doi:10.1016/0040-6090(94)06462-8

34. Evans, J. H. J. Nucl. Mater. 1978, 76-77, 228-234. doi:10.1016/0022-3115(78)90145-9

35. Yoon, J.-H.; Kim, W.-M.; Park, J.-K.; Baik, Y.-J.; Seong, T.-Y.; Jeong, J.-h. Prog. Photovoltaics 2014, 22, 69-76. doi:10.1002/pip.2338

36. Xu, X.; Qu, Y.; Barrioz, V.; Zoppi, G.; Beattie, N. S. RSC Adv. 2018, 8, 3470-3476. doi:10.1039/c7ra13336g

37. Jubault, M.; Ribeaucourt, L.; Chassaing, E.; Renou, G.; Lincot, D.; Donsanti, F. Sol. Energy Mater. Sol. Cells 2011, 95, S26-S31. doi:10.1016/j.solmat.2010.12.011

38. Yoon, J.-H.; Cho, S.; Kim, W. M.; Park, J.-K.; Baik, Y.-J.; Lee, T. S.; Seong, T.-Y.; Jeong, J.-h. Sol. Energy Mater. Sol. Cells 2011, 95, 2959-2964. doi:10.1016/j.solmat.2011.02.030

39. Bollero, A.; Andrés, M.; García, C.; Abajo, J. d.; Gutiérrez, M. T. Phys. Status Solidi A 2009, 206, 540-546. doi:10.1002/pssa.200824405

40. Sun, D.; Xu, S.; Zhang, L.; Wei, C.; Li, Y.; Chi, Y.; Zhao, Y.; Zhang, X. Appl. Surf. Sci. 2017, 413, 408-413. doi:10.1016/j.apsusc.2017.04.066

41. Ruckh, M.; Schmid, D.; Kaiser, M.; Schäffler, R.; Walter, T.; Schock, H. Sol. Energy Mater. Sol. Cells 1996, 41-42, 335-343. doi:10.1016/0927-0248(95)00105-0

42. Wei, S.-H.; Zhang, S. B.; Zunger, A. J. Appl. Phys. 1999, 85, 7214-7218. doi:10.1063/1.370534

43. Erslev, P. T.; Lee, J. W.; Shafarman, W. N.; Cohen, J. D. Thin Solid Films 2009, 517, 2277-2281. doi:10.1016/j.tsf.2008.10.140

44. Prabhakar, T.; Jampana, N. Sol. Energy Mater. Sol. Cells 2011, 95, 1001-1004. doi:10.1016/j.solmat.2010.12.012

45. Johnson, J. L.; Nukala, H.; Bhatia, A.; Oo, W. M. H.; Rieth, L. W.; Scarpulla, M. A.; Lund, E. A. MRS Online Proc. Libr. 2010, 1268, 1268-EE03-03. doi:10.1557/proc-1268-ee03-03

46. Pianezzi, F.; Nishiwaki, S.; Kranz, L.; Sutter-Fella, C. M.; Reinhard, P.; Bissig, B.; Hagendorfer, H.; Buecheler, S.; Tiwari, A. N.

Prog. Photovoltaics 2015, 23, 892-900. doi:10.1002/pip.2503

\section{License and Terms}

This is an Open Access article under the terms of the Creative Commons Attribution License (http://creativecommons.org/licenses/by/4.0). Please note that the reuse, redistribution and reproduction in particular requires that the authors and source are credited.

The license is subject to the Beilstein Journal of Nanotechnology terms and conditions: (https://www.beilstein-journals.org/bjnano)

The definitive version of this article is the electronic one which can be found at:

doi:10.3762/bjnano.9.252 